\title{
Serological Heterogeneity of Mycoplasma pulmonis
}

\author{
By KATHRYN A. FORSHAW* AND R. J. FALLON \\ Department of Pathology, Ruchill Hospital, Glasgow, G20 $9 \mathrm{NB}$
}

(Received 29 February 1972 ; revised 9 May 1972)

\begin{abstract}
SUMMARY
Twelve stock and 15 freshly isolated strains of Mycoplasma pulmonis were examined and compared using four serological techniques. Complement fixation tests and inhibition of growth on solid medium showed that the strains were all $M$. pulmonis, although, with some strains, only one of these techniques gave an unequivocal result. These tests were confirmed to be specific only at a species level. Gel diffusion and metabolic inhibition techniques revealed heterogeneity of the strains at the subspecies level. The relationship between some strains was statistically significant and stable in vitro and some small groups could be defined.

These serogroups bore no relationship to groups formed on the basis of protein patterns produced on polyacrylamide gel electrophoresis of strains of Mycoplasma pulmonis.
\end{abstract}

\section{INT RODUCTION}

Until recently serological studies failed to show any notable heterogeneity within the species Mycoplasma pulmonis. Agglutination tests (Klieneberger, 1938), complement fixation (Lemcke, 1961, 1964) and indirect fluorescent antibody tests (Tully, 1965) indicated similarity between the strains examined.

Fallon \& Jackson (1967), using several serological methods, found quantitative differences between the titres of antisera in reactions with homologous and heterologous strains of Mycoplasma pulmonis. These differences pointed to the possibility of heterogeneity within the species, as had been noted with $M$. hominis by Purcell et al. (1967). Deeb \& Kenny (1967) suggested that strains of $M$. pulmonis might be differentiated on the possession of a heatstable, type-specific complement-fixing antigen.

In view of these findings it was decided to investigate a number of laboratory-adapted, as well as freshly isolated, strains of Mycoplasma pulmonis to see if serotypes could be distinguished at the subspecies level.

\section{METHODS}

Organisms. The mycoplasma strains, the sources from which they were derived and the method used to confirm their identity are given in the accompanying paper (Forshaw, 1972). The following strains were also included: MI (received from Dr R. Lemcke), F, B, TUCK, IOI3B, G-I, G-2, G-4 (received from Miss A. Hill), and Mycoplasma pneumoniae (FH strain received from Dr B. Andrews).

Media and growth conditions. The media used are described in Forshaw (1972). When mycoplasma suspensions were needed for the production of antisera in rabbits, rabbit serum was substituted for horse serum in the medium and calf thymus DNA was omitted. At first $0.2 \%$ cholesterol was added to the medium because of the reported deficiency of this growth factor in rabbit serum. Growth was satisfactory, however, in the absence of added

* Present address: Salmonella Reference Laboratory, Central Public Health Laboratory, Colindale Avenue, London, NW9 5HT. 
cholesterol and it was omitted from the medium used for the production of antigens for injection.

Antigens for complement fixation and gel diffusion tests. Log-phase cultures were used to inoculate liquid medium to which had been added I \% (w/v) glucose and $0.002 \%(\mathrm{w} / \mathrm{v})$ phenol red. The medium was incubated at $37^{\circ} \mathrm{C}$ until the colour change in the medium indicated a drop of $0.5 \mathrm{pH}$ unit. Organisms were harvested by centrifugation at $33400 \mathrm{~g}$ for $30 \mathrm{~min}$ and then washed three times with phosphate-buffered saline (PBS) (pH 7.2) at $46500 \mathrm{~g}$ for $20 \mathrm{~min}$. The pellet was finally suspended to $\mathrm{I} / 200$ of the original volume in PBS with added calcium and magnesium salts (Grist, Ross, Bell \& Stott, I966). This suspension was disrupted for $10 \mathrm{~min}$ in an MSE $60 \mathrm{~W}$ ultrasonic disintegrator and was stored at $-20^{\circ} \mathrm{C}$.

Cultures for metabolic inhibition tests. Log-phase cultures were distributed in small portions and stored at $-70{ }^{\circ} \mathrm{C}$. When required, a portion was thawed and diluted in broth containing glucose and phenol red, to give a suspension of organisms which, by preliminary testing, was known to produce a colour change corresponding to $0.5 \mathrm{pH}$ unit, after approximately 3 days of incubation at $33^{\circ} \mathrm{C}$.

Antigens for immunization of rabbits. Strains of mycoplasmas were cloned at least three times and were then passaged three times in rabbit serum medium to remove heterologous protein from the material to be used for immunization. Log-phase organisms were harvested and washed three times in PBS and finally resuspended in PBS to $1 / 100$ of the original culture volume. The antigen was either used immediately or stored at $-20{ }^{\circ} \mathrm{C}$ prior to use.

Immunization schedules. A I ml sample of whole organism suspension was emulsified with I ml of Freund's complete adjuvant. The rabbit was bled by cardiac puncture to obtain pre-immune serum and was then given $\mathrm{I} \mathrm{ml}$ of antigen-adjuvant mixture intramuscularly into each hind leg. After 3 weeks the animal was given a further injection of $0.5 \mathrm{ml}$ of organism suspension intravenously. Intravenous injection was repeated at weekly intervals until an immune serum, satisfactory as measured by the growth inhibition and gel diffusion tests, was obtained. A short immunization schedule was preferred, to avoid producing a less specific antiserum.

Inhibition by immune serum of growth on solid medium. The method used was that of Clyde (1964). Agar plates were flooded with broth culture diluted so as to give, following incubation, a semiconfluent growth of mycoplasmas. The plates were dried and sterile filter-paper discs of $6 \mathrm{~mm}$ diameter impregnated with $0.02 \mathrm{ml}$ of unheated immune antiserum were placed on the surface of the agar. Discs either untreated or impregnated with preimmune rabbit serum were used as controls. The plates were incubated at $37^{\circ} \mathrm{C}$ for 3 days, or until colonies were visible. When viewed by reflected light, the width of the zones of inhibition round the paper discs was measured from the edge of the disc to the nearest colonies. Tests of inhibition of growth of a particular strain by all the antisera shown in Table I were set up on one day using one suspension so that the results would be directly comparable.

Complement fixation (C.F.) test. The method used was that of Bradstreet \& Taylor (1962) as modified by Grist et al. (I966). Antigens and inactivated antisera were titrated in a chessboard fashion and the results were recorded at a $75 \%$ end point.

Metabolic inhibition (M.I.) test. This test was performed using glucose as the substrate (Taylor-Robinson, Purcell, Wong \& Chanock, I966). Unheated guinea-pig serum was incorporated in the test medium at a final concentration of $6 \%$, except where this was inhibitory to the strain under examination, in which case a final concentration of $3 \%$ was used (D. Taylor-Robinson, personal communication). Although the guinea-pig serum was not necessary to demonstrate metabolic inhibition, its addition stabilized and enhanced the titre which 
Table I. Inhibition of growth of strains of Mycoplasma pulmonis
on solid medium by antiserum

The figures represent the width of the zones of inhibition in $\mathrm{mm}$ from the edge of the filter-paper discs to the first colonies. Figures in bold type represent the homologous reaction.

\begin{tabular}{|c|c|c|c|c|c|c|c|c|c|c|}
\hline \multirow[b]{2}{*}{ Mycoplasma } & \multicolumn{10}{|c|}{ Antiserum to } \\
\hline & Kon & M2 & M50 & Ash & Negroni & 63 & 47 & 880 & Cheng & Strain G \\
\hline Kon & 7 & 4 & $3 \cdot 5$ & 4.5 & 4.5 & $5 \cdot 5$ & I & $3 \cdot 5$ & 4 & $2 \cdot 5$ \\
\hline M2 & $5 \cdot 5$ & $5 \cdot 5$ & 2 & $3 \cdot 5$ & $2 \cdot 5$ & $4 \cdot 5$ & 0 & 4 & $4 \cdot 5$ & $<$ I \\
\hline M50 & $6 \cdot 5$ & $2 \cdot 5$ & $4 \cdot 5$ & 3.5 & $4 \cdot 5$ & 4 & $<\mathrm{I}$ & 4 & 5 & $I \cdot 5$ \\
\hline Ash & $4 \cdot 5$ & $2 \cdot 5$ & 3 & 5 & 4 & 5 & $<\mathrm{I}$ & 3.5 & $4 \cdot 5$ & $2 \cdot 5$ \\
\hline Negroni & $4 \cdot 5$ & 2 & $2 \cdot 5$ & 5 & $7 \cdot 5$ & 5 & $<\mathrm{I}$ & $3 \cdot 5$ & $4 \cdot 5$ & 5 \\
\hline 63 & 6 & $3 \cdot 5$ & 4 & 4 & 4 & $7 \cdot 5$ & $<\mathbf{I}$ & 4 & 5 & 3 \\
\hline 47 & 3 & $2 \cdot 5$ & 3 & 3 & 3 & 4 & $\mathbf{I}$ & 3 & $5 \cdot 5$ & $I \cdot 5$ \\
\hline 880 & $6 \cdot 5$ & 5 & 3 & $5 \cdot 5$ & 4 & 5 & $I \cdot 5$ & $7 \cdot 5$ & 5 & 2 \\
\hline Cheng & 7 & 4.5 & $4 \cdot 5$ & 3 & $5 \cdot 5$ & $6 \cdot 5$ & 3 & 5 & $5 \cdot 5$ & $2 \cdot 5$ \\
\hline Strain G & $4 \cdot 5$ & $<\mathrm{I}$ & $I \cdot 5$ & $6 \cdot 5$ & $8 \cdot 5$ & $4 \cdot 5$ & 0 & $4 \cdot 5$ & 6 & 6 \\
\hline
\end{tabular}

was held for a longer period of time. This made the test easier to read and a more accurate determination of the maximum serum titre was obtained.

Agar-gel diffusion. The antigen used contained approximately 2 to $3 \mathrm{mg}$ protein $/ \mathrm{ml}$. The gels of I \% Ionagar no. 2 in water were poured on lantern slides and patterns were cut to produce wells $3 \mathrm{~mm}$ in diameter and $2 \mathrm{~mm}$ deep with their centres ro $\mathrm{mm}$ apart. The gels were incubated in moist conditions for $48 \mathrm{~h}$ at room temperature and line development was recorded at 24 and $48 \mathrm{~h}$.

\section{RESULTS}

Inhibition of growth on solid medium. Typical results of tests with strains for which homologous antisera were available are shown in Table $\mathrm{I}$. The Table should only be read horizontally as the zone sizes produced by a particular serum varied with the homologous strain from test to test (Clyde, 1964; Fallon \& Jackson, 1967) although the relationship between the zone sizes produced by the various sera with a given strain tended to be the same. The results with one strain therefore should be regarded as a complete test (see above). In most, but not all, instances a serum produced the greatest zone of inhibition with the homologous mycoplasma. No clear-cut groupings were evident from this test, which is only specific at the species level, but it is noteworthy that a serum of low potency, such as that to strain 47 , would fail to identify a number of the other strains as Mycoplasma pulmonis, and also that strains G and M2 appear to be very different as neither serum inhibited the growth of the other strain.

The finding that homologous serum tends to produce a larger zone of inhibition of a mycoplasma has also been reported by Taylor-Robinson \& Berry (1969). When a heavy inoculum was used to produce confluent growth, but not heavy enough to inhibit zone production, some strains formed a ring of precipitation with a few of the more potent antisera. This phenomenon was previously recorded by Dinter \& Taylor-Robinson (1969), who observed multiple rings and correlated the number of rings with the sensitivity to antibody of the strains of Mycoplasma hyorhinis which they examined. If growth was confluent, we often noted resistant colonies growing in the zone of inhibition. When selected, these colonies gave rise to another population of mixed sensitivity. This phenomenon has been described and investigated by Hayflick \& Stanbridge (1967). In the present study the sensitivity of resistant colonies was checked to ensure that a mixture of species had not occurred. 


\section{Table 2. Complement fixation with strains of Mycoplasma pulmonis}

The figures are the reciprocals of the dilution of antiserum which gives $3+$ fixation with the optimal dilution of antigen. Figures in bold type represent the homologous reaction.

Antiserum to

\begin{tabular}{|c|c|c|c|c|c|c|c|c|c|c|c|}
\hline \multirow[b]{2}{*}{ Antigen } & \multirow[b]{2}{*}{ Kon } & \multirow[b]{2}{*}{ Ash } & \multirow[b]{2}{*}{ Negroni } & \multirow[b]{2}{*}{880} & \multirow[b]{2}{*}{ M2 } & \multirow[b]{2}{*}{ M5O } & \multirow[b]{2}{*}{63} & \multicolumn{3}{|c|}{ Strain } & \multirow{2}{*}{$\begin{array}{l}\text { Sabin } \\
\text { type C }\end{array}$} \\
\hline & & & & & & & & 47 & G & Cheng & \\
\hline Kon & 1024 & 512 & 256 & 512 & 256 & 1024 & 1024 & I 28 & 64 & IO24 & I 28 \\
\hline Ash & 128 & 1024 & 512 & 256 & 128 & 512 & 512 & 64 & 256 & 256 & 128 \\
\hline Negroni & I 28 & 1024 & 1024 & 1024 & 128 & 512 & 2048 & I 28 & 256 & 512 & 128 \\
\hline 880 & I 28 & 512 & 1024 & 1024 & 128 & 512 & 512 & 64 & 128 & 512 & 64 \\
\hline M2 & 1024 & 256 & 512 & 512 & 256 & 256 & 2048 & 64 & 128 & 1024 & 128 \\
\hline M50 & IO24 & 1024 & 128 & 512 & 256 & 512 & 1024 & 64 & 128 & 1024 & 64 \\
\hline 63 & 256 & 1024 & I 28 & 256 & 64 & 64 & 1024 & 64 & 64 & 128 & 64 \\
\hline 47 & 256 & 1024 & 256 & 512 & 256 & 256 & 512 & 256 & 128 & 512 & 512 \\
\hline Strain G & 1024 & 512 & 512 & 512 & I 28 & 256 & 1024 & I 28 & 512 & 1024 & 256 \\
\hline Cheng & 128 & 256 & 128 & 128 & 256 & 64 & I 28 & 32 & 64 & 128 & 128 \\
\hline Sabin type c & 2048 & 1024 & 512 & $5 \mathrm{I} 2$ & 512 & 1024 & 1024 & 64 & 156 & 1024 & 512 \\
\hline MI & I 28 & 128 & 128 & 256 & 128 & 64 & I 28 & I 28 & 64 & 256 & 64 \\
\hline Strain $\mathrm{F}$ & 1024 & 1024 & I024 & 512 & $5 \mathrm{I} 2$ & $5 \mathrm{I} 2$ & I024 & 256 & 256 & 512 & 1024 \\
\hline Strain B & 1024 & 1024 & 512 & 512 & 64 & 512 & 1024 & 64 & I 28 & 512 & 256 \\
\hline M72L & 1024 & 1024 & 512 & 256 & 512 & 512 & 1024 & 32 & I 28 & 1024 & 256 \\
\hline$M$. neur & 32 & 32 & $<$ I6 & 64 & 32 & 32 & 16 & 32 & I6 & 32 & N.T. \\
\hline M. fermentans & 32 & 16 & $<16$ & 128 & 16 & 16 & $<16$ & 16 & $<$ I6 & 16 & N.T. \\
\hline
\end{tabular}

N.T. $=$ not tested.

Freshly isolated strains of $M$. pulmonis were inhibited by the antisera listed in Table I with widely differing zone sizes. Again, some were so small that it might have been difficult to classify the strain as $M$. pulmonis if only one antiserum had been used.

Complement fixation test. The relationships between 15 strains of Mycoplasma pulmonis were examined by this test. The unrelated strains $M$. neurolyticum and $M$. fermentans were included as controls. These 17 strains of mycoplasmas were examined with antisera to II strains of $M$. pulmonis. The results are shown in Table 2.

A twofold difference on either side of the average titre was allowed for experimental error. Some strains seemed more closely related than others, but as found by Lemcke (1964) C.F. did not differentiate strains below species level. It is worth noting that some heterologous reactions, e.g. antiserum to strain 880 with Cheng antigen, were of the same order as with the unrelated species Mycoplasma fermentans. This suggests that C.F. should not be used alone as a method of species identification.

Effect of heat on C.F. antigens. Six strains of Mycoplasma pulmonis were examined for the presence of a heat-stable, type-specific antigen of the kind described by Deeb \& Kenny (I967). These authors found such an antigen in the strains 63,47 and Kon in that the boiled antigens, which were organism concentrates held at $100{ }^{\circ} \mathrm{C}$ for $30 \mathrm{~min}$, were as active in the homologous reaction as untreated antigens, but there was a decrease in antiserum titre of four- to eightfold in heterologous reactions. In the present investigation results shown in Table 3 illustrate that the antiserum titres in both homologous and heterologous reactions were reduced when 'boiled' antigens (sonicates held at $100^{\circ} \mathrm{C}$ for $30 \mathrm{~min}$ ) were used. In only one instance when strains 63 and 47 were tested with antiserum to 63 , was there evidence of a heat-stable, type-specific antigen in strain 63 . These results do not therefore confirm the findings of Deeb \& Kenny (1967).

Metabolic inhibition (M.I.) test. The results of tests with nine strains and their antisera are 
Table 3. The effect of heat on C.F. antigens of strains of Mycoplasma pulmonis

The figures are the reciprocals of the antiserum dilutions which give $3+$ fixation, i.e. a $75 \%$ end point, with the optimal dilution of antigen. Figures in bold type represent the homologous reaction.

Antiserum to

\begin{tabular}{|c|c|c|c|c|c|c|}
\hline Antigen & Kon & M2 & Ash & Negroni & 47 & 63 \\
\hline Kon & 1024 & 512 & 1024 & 256 & 512 & 1024 \\
\hline Kon boiled* & 256 & 64 & 256 & 128 & 32 & 512 \\
\hline M2 & 512 & 256 & 512 & I 28 & N.T. & N.T. \\
\hline M2 boiled* & 128 & 64 & 128 & 32 & N.T. & N.T. \\
\hline Ash & 512 & I 28 & 1024 & 256 & N.T. & N.T. \\
\hline Ash boiled* & I 28 & $\mathrm{I} 28$ & 512 & 128 & N.T. & N.T. \\
\hline Negroni & 2048 & 512 & 1024 & 1024 & N.T. & N.T. \\
\hline Negroni boiled* & 256 & 64 & $5 \mathrm{I} 2$ & 256 & N.T. & N.T. \\
\hline 47 & N.T. & N.T. & N.T. & N.T. & 128 & 1024 \\
\hline 47 boiled* & N.T. & N.T. & N.T. & N.T. & 64 & 64 \\
\hline 63 & N.T. & N.T. & N.T. & N.T. & 64 & 1024 \\
\hline 63 boiled* & N.T. & N.T. & N.T. & N.T. & 64 & 1024 \\
\hline
\end{tabular}

N.T. $=$ not tested.

* Antigens held at $100{ }^{\circ} \mathrm{C}$ for $30 \mathrm{~min}$.

Table 4. Relationship between strains of Mycoplasma pulmonis as shown by metabolic inhibition tests

Titres are expressed as the reciprocals of the highest dilution of antiserum which show no colour change when the control cup changed $0.5 \mathrm{pH}$ unit. Figures in bold type represent the homologous reaction.

Antiserum to

\begin{tabular}{|c|c|c|c|c|c|c|c|c|c|}
\hline Organism & Negroni & Ash & Kon & M2 & M50 & 880 & 63 & Strain G & Cheng \\
\hline \multicolumn{10}{|l|}{ M. pulmonis strains } \\
\hline Negroni & $25^{6} 000$ & 1024 & 16000 & 4096 & 2048 & 4096 & 16000 & 4096 & 8192 \\
\hline Ash & 8192 & 8 r92 & 4096 & 2048 & 2048 & 4096 & 32000 & 4096 & 2048 \\
\hline Kon & 8192 & 4096 & 32000 & 8192 & 32000 & 4096 & 32000 & 4096 & 64000 \\
\hline M2 & 4096 & 512 & 4096 & 256000 & 4096 & $5 \mathrm{I} 2$ & 4096 & I 6000 & 2048 \\
\hline M50 & 64000 & 4096 & 4096 & 16000 & 8192 & $8 I 92$ & 32000 & I6 000 & 32000 \\
\hline 880 & 32000 & 2048 & 4096 & 2048 & 2048 & 16000 & 32000 & 4096 & 16000 \\
\hline 63 & 32000 & 4096 & 4096 & 8192 & I 024 & 8192 & 32000 & 64000 & I 6000 \\
\hline Strain G & 64000 & 32000 & 1024 & 2048 & 4096 & 8192 & 8192 & 64000 & 8192 \\
\hline Cheng & 4096 & 2048 & 8192 & 8192 & 4096 & 8192 & 2048 & 1024 & 4096 \\
\hline MI & 2048 & I 024 & 4096 & 512 & 512 & 4096 & I6 600 & I 024 & 4096 \\
\hline 47 & 8192 & 4096 & 4096 & I 024 & I 6000 & 8192 & 16000 & 512 & 16000 \\
\hline M72L & $8 I 92$ & I 024 & I 024 & 4096 & 4096 & 4096 & 32000 & 512 & I 6000 \\
\hline Sabin type $\mathrm{C}$ & I6 600 & 4096 & 8192 & 2048 & 8 I 92 & 8192 & 32000 & 32000 & 8192 \\
\hline Strain B & 64000 & 8192 & 4096 & I 024 & 512 & 32000 & I6 000 & I 024 & 2048 \\
\hline Strain $\mathrm{F}$ & 32000 & 4096 & I6 000 & 8192 & 512 & I 6000 & 32000 & 4096 & 4096 \\
\hline \multicolumn{10}{|l|}{ Controls } \\
\hline M. fermentans & $<8$ & N.T. & $<8$ & N.T. & N.T. & $<8$ & N.T. & N.T. & N.T. \\
\hline M. neurolyticum & $<8$ & N.T. & 16 & N.T. & N.T. & 16 & N.T. & N.T. & N.T. \\
\hline M. pneumoniae & $<8$ & N.T. & $<8$ & N.T. & N.T. & $<8$ & N.T. & N.T. & N.T. \\
\hline
\end{tabular}

N.T. $=$ not tested.

shown in Table 4. Serum titres never varied by more than one dilution from the mean in repeated tests, a degree of variation similar to that noted by Gourlay \& Leach (1970) in studies with strains of Mycoplasma dispar sp.nov. In some instances the homologous reaction gave the highest serum titre, but some strains were inhibited to a greater extent by heterologous sera, e.g. Ash serum had a titre of 8192 with Ash but 32000 with strain G. 
Table 5. Relationship between nine strains of Mycoplasma pulmonis as shown by M.I. tests

Relatedness $\left(\log _{2} R\right)$ from two replicate tests.

\begin{tabular}{|c|c|c|c|c|c|c|c|c|}
\hline Organism & Ash & Kon & M2 & M50 & 880 & 63 & G & Cheng \\
\hline Negroni & $-8 \cdot 5$ & $-6 \cdot 5$ & $-14 \cdot 0$ & $-3 \cdot 5$ & -5.5 & $-5 \cdot 0$ & $-7 \cdot 0$ & $-4 \cdot 0$ \\
\hline Ash & . & -5.5 & -13.5 & $-3 \cdot 0$ & $-4 \cdot 0$ & $-1 \cdot 0$ & $-2 \cdot 5$ & $-2 \cdot 0$ \\
\hline Kon & . & . & $-12 \cdot 0$ & -0.5 & $-5 \cdot 5$ & $-3 \cdot 0$ & -10.0 & $+2 \cdot 5$ \\
\hline M2 & . & . & . & $-8 \cdot 0$ & -14.0 & $-10 \cdot 0$ & -12.5 & $-7 \cdot 5$ \\
\hline M5O & . & . & . & . & $-3 \cdot 5$ & -2.5 & -4.5 & +3.0 \\
\hline 880 & . & . & . & . & . & $-\mathrm{I} \cdot 5$ & -5.5 & +0.5 \\
\hline 63 & . & . & . & . & . & . & -2.5 & 0 \\
\hline G & . & . & . & . & . & . & . & $-3 \cdot 0$ \\
\hline
\end{tabular}

Ninety-five per cent confidence interval $-2 \cdot 47$ to $+2 \cdot 47$.

Table 6. Titres of Mycoplasma pulmonis antisera in metabolic inhibition tests with recently isolated strains of $M$. pulmonis

\begin{tabular}{lrrrrr} 
Strain of & \multicolumn{5}{c}{ Antiserum } \\
$M$. pulmonis & 880 & Negroni & 63 & \multicolumn{1}{c}{ Ash } & Kon \\
Homologous & 16000 & 256000 & 32000 & 8192 & 32000 \\
MacIndoe & 32000 & 128000 & 64000 & 128000 & 16000 \\
Tuck & 32000 & 16000 & 32000 & 128000 & 16000 \\
RBU & 32000 & 4096 & 64000 & 64000 & 64000 \\
IOI4NP & 8192 & 2048 & 16000 & 4096 & 4096
\end{tabular}

Taylor-Robinson \& Berry ( 1969 ) reported similar results with strains of $M$. gallisepticum. Evidence for relationship between strains was looked for on the basis of reciprocal inhibition of growth of strains by their antisera and the results were analysed statistically by the method of Alling (1967) (Table 5). Overall, dissimilarities were more evident than similar groupings, but the following strains appeared to be closely related: Kon and M50; Ash, 63 and Cheng; 880,63 and Cheng; and possibly G, Ash and 63 (just outside confidence limits). An interesting finding was that freshly isolated strains tended to be inhibited by higher dilutions of serum than the established strains of M. pulmonis (Table 6.).

Agar-gel diffusion. Homologous reactions, between an individual strain and the antiserum raised to it, were frequently more dense than heterologous reactions and were thus more distinct. This confirmed the results of Fallon \& Jackson (1967).

The extent of cross-reaction between strains of Mycoplasma pulmonis in the gel diffusion test, however, was found to vary. Some strains reacted specifically with their own antisera and crossover with others was negligible (Fig. I). Some strains shared minor antigens as indicated by fine lines of identity, whilst others shared major antigens indicated by heavy lines of identity (Fig. 2). The relationship between other strains was less well defined, especially if a weak antiserum was used. It was important therefore to use a potent antiserum for the examination of strains by this method.

The difficulty of interpreting diffusion patterns, i.e. deciding which line represented the strain specific antigen, could not be resolved; e.g. at a dilution of $I$ in 2, antigens of Kon and M50 could be distinguished in their reaction to Kon, but at a dilution of I/8 the two strains seemed identical (Fig. 3), i.e. the distinguishing antigen did not appear to be a major antigen.

Heat-stability of antigens. Several strains of Mycoplasma pulmonis were investigated to see if the gel diffusion antigens were heat-stable (i.e. stable to holding at $100{ }^{\circ} \mathrm{C}$ for $30 \mathrm{~min}$ ). 

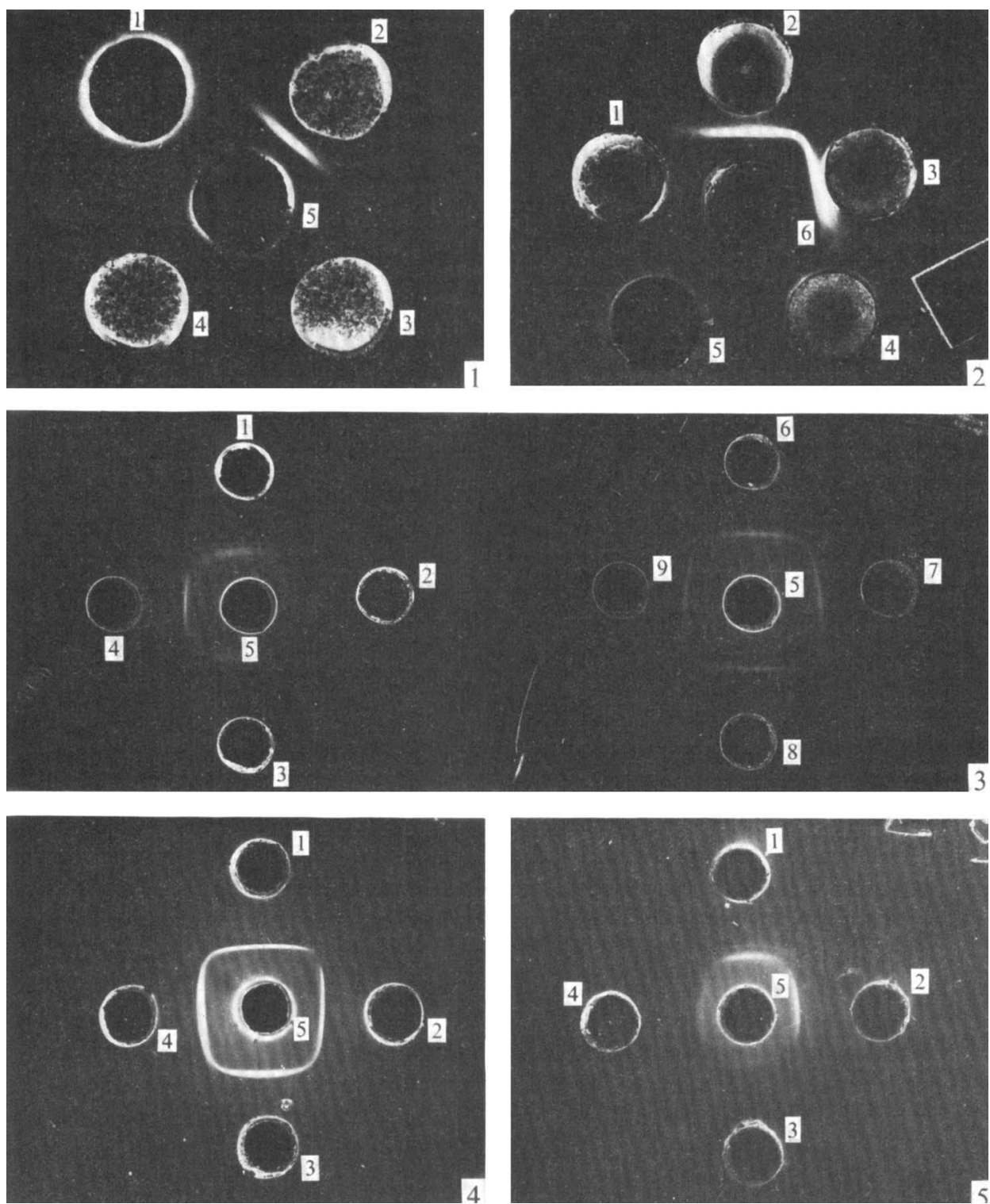

Fig. I. Agar double diffusion reaction between uninoculated culture medium (I), Mycoplasma pulmonis strains 880 (2), Negroni (3), Kon (4) and antiserum to 880 (5).

Fig. 2. Agar double diffusion reaction between Mycoplasma pulmonis strains $\mathrm{M}_{1}(\mathrm{I})$, Kon (2), $M_{2}$ (3), Cheng (4) uninoculated culture medium control (5) and antiserum to Kon (6). Kon and $M_{2}$ share a major antigen $M_{1}$ and Cheng share minor antigens with Kon and $M_{2}$ respectively.

Fig. 3. Agar double diffusion reaction between Kon antiserum (5) and suspensions of Mycoplasma pulmonis strains Kon and M50 showing effect of dilution of antigen. (a) Undiluted: Kon (I) and M50 (3); (b) diluted I in 2 : Kon (4) and M50 (2); (c) diluted I in 4 : Kon (6) and M50 (8); (d) diluted $\mathrm{I}$ in 8 ; Kon (9) and M50 (7).

Fig. 4. Agar double diffusion reaction between heated and unheated Mycoplasma pulmonis suspensions and Negroni antiserum (5) showing a heat-soluble major antigen. (a) Unheated Negroni (I) and strain B (2); (b) boiled Negroni (4) and strain B (5).

Fig. 5. Agar double diffusion reaction between Mycoplasma pulmonis strains Kon and M50 and Kon antiserum (5) showing a shared heat-labile antigen. (a) Unheated Kon (I) and M5O (2); (b) boiled Kon (4) and M50 (3). 
Table 7. Groups of strains indicated by the gel diffusion test

$\begin{array}{llc}\text { Group I } & \text { Group 2 } & \text { Group 3 } \\ \text { Cheng } & \text { Ash } & 880 \\ \text { Kon } & \text { MacIndce } & \text { RBU } \\ \text { M50 } & \text { Negroni } & \text { TUCK } \\ & \text { Strain B } & \\ & \text { Strain G } & \end{array}$

The major precipitating antigen of most strains was heat-stable and there was no change in the precipitation patterns following heating; e.g. strains Negroni and B had identical precipitation patterns whether the antigens were unheated or heated (Fig. 4). Strains Kon and M50 shared a heat-labile antigen which reacted with antiserum to Kon (Fig. 5).

Trypsin treatment of antigen. Prior treatment of antigens with trypsin abolished the precipitation reaction, thus showing that the major antigens were proteins.

Some strains gave strong reactions in gel diffusion tests and shared major antigens. Relationship was accepted if strains shared at least one major precipitation line. On this basis, strains which seemed closely related fell into three groups (Table 7). The strains in the three groups did not all have strong two-way relationships with fellow group members. Some strains possessed antigens which were shared with members of more than one of these groups, but none of the shared antigens was a major antigen.

\section{DISCUSSION}

Species identification in mycoplasmas may be achieved with relative ease, but only a few species have been studied at the subspecies level and these species seem to vary in their degree of intraspecies heterogeneity. Mycoplasma hominis has clearly been shown to have distinguishable subtypes (Somerson, Reich, Walls, Chanock \& Weissman, 1966, Purcell et al. 1967; Hollingdale \& Lemcke, 1969). Cottew \& Leach (1969) showed, in studies on M. mycoides var. mycoides and $M$. mycoides var. capri, that among these strains there are some with lesser degrees of relationship than others. Recently Taylor-Robinson, Martin-Bourgon, Watanabe \& Addey (I97I) have shown that T-strain mycoplasmas isolated from various animal species can be distinguished by serological techniques, though similar in their special ability to metabolize urea and in their polyacrylamide-gel patterns. Other mycoplasma species are principally defined on the basis of serological techniques with metabolic differences playing only a crude identifying role. Further investigations are required to establish the criteria for species and subtypes so that the same standards for identification will apply to all the strains of mycoplasmas being studied.

In the present study both serological and electrophoretic (Forshaw, 1972) methods were used. As detailed in Results, complement fixation and growth-inhibition tests showed no intraspecies groupings, but the metabolic inhibition test indicated possible relationships between the few strains. Fallon \& Jackson (1967) could distinguish between several strains of Mycoplasma pulmonis on the quantitative difference between homologous and heterologous serum titres, and suggested that this might be used as a method of recognizing groups within the species. When examined by the metabolic inhibition test, however, only a small number of the strains of $M$. pulmonis used in the present study seemed to be related, while all others were unrelated, indicating a wide degree of heterogeneity within the species. Freshly isolated strains were very susceptible to the action of antiserum in the metabolic inhibition test. The reason for their sensitivity is unknown. 
The gel-diffusion test has been used previously in identification and classification studies (Taylor-Robinson, Somerson, Turner \& Chanock, I963; Lemcke, I964; Fallon \& Jackson, 1967). We have used the test to analyse the qualitative relationships between strains. Different degrees of relationship were recorded and groups of related strains were suggested. A number of strains, however, were not related to each other. The fact that strains could be distinguished without the necessity for preparing heated antigens is at variance with the findings of Deeb \& Kenny (1967).

Further studies were made on soluble and membrane antigens of several strains of $\mathrm{Myco}$ plasma pulmonis to see if strain specificity could be associated firmly with one or other fraction. Clear-cut relationships could not be established using the antigens prepared, since it was not found possible to prepare one fraction free from contaminating amounts of the other.

In summary, the results of the present investigation have shown that all the isolates of Mycoplasma pulmonis were related, although individual tests may not have given this impression. Serological analysis produced some groups of strains which were not always distinct from one another, because some strains shared antigens with members of more than one group. With the exception that Ash and 63 fell into the same group, both by the electrophoretic and metabolic inhibition technique, the groups of strains with similar electrophoretic patterns (Forshaw, 1972) were not the same as those formed from the results of the serological studies. This is not unexpected, since in the serological studies, antigens are being analysed, whereas in the electrophoretic studies, extracted proteins are being analysed. Small variations in the protein make-up of the organisms may not be detectable by electrophoresis but may be detected by more specific serological methods. However, electrophoresis is speedy, and straightforward to perform without the necessity for preparing specific antisera, and provided that a range of standard patterns is available for comparison, species identification should easily be made.

The reproducibility of the serological results together with the electrophoretic results indicate that there are recognizable stable differences between strains of Mycoplasma pulmonis under laboratory conditions. The subdivision of any microbial species depends on the presence of such reproducible differences. It would, however, be of considerable interest to passage in vivo strains of $M$. pulmonis which have been well characterized by the techniques described, in order to assess the stability of these characteristics under natural conditions, and to determine which tests (including electrophoresis) were of greatest value in recognizing similar strains as an aid to epidemiological studies.

We are indebted to Dr R. M. Lemcke and Dr M. R. Hollingdale for helpful discussions and Mrs A. C. Ramage for secretarial assistance. This work was carried out during the tenure of one of the authors (K.A.F.) of the Sir Maurice Bloch Medical Research Fellowship at the Department of Infectious Diseases, Glasgow University. The materials and most of the equipment were provided from a grant by the Secretary of State for Scotland, made to Dr R. J. Fallon on the recommendation of the Advisory Committee on Medical Research. 


\section{REFERENCES}

Alling, D. W. (1967). Tests of relatedness. Biometrika 54, 459-466.

Bradstreet, C. M. P. \& TAylor, C. E. D. (1962). Technique of complement-fixation test applicable to the diagnosis of virus diseases. Monthly Bulletin of the Ministry of Health 21, 96-104.

CotTew, C. S. \& LeACH, R. H. (1969). Mycoplasmas of cattle, sheep and goats. In The Mycoplasmatales and L-phase of Bacteria, pp. 527-570. Edited by L. Hayflick. Amsterdam: North Holland Publishing Co.

Clyde, W. A. (I964). Mycoplasma species identification based upon growth inhibition by specific antisera. Journal of Immunology 92, 958-965.

DEEB, B. J. \& KENNY, G. E. (1967). Characterization of Mycoplasma pulmonis variants isolated from rabbits. II. Basis for differentiation of antigenic subtypes. Journal of Bacteriology 93, 1425-I429.

DinTER, Z. \& TAYLOR-Robinson, D. (1969). Susceptibility and resistance of various strains of Mycoplasma hyorhinis to antisera, polymyxins and low pH values. Journal of General Microbiology 57, 263-272.

FALlON, R. J. \& JACKSON, D. K. (1967). The relationship between a rodent mycoplasma, Mycoplasma pulmonis, and certain mycoplasmas isolated from tissue cultures inoculated with material from patients with leukaemia. Laboratory Animals I, 55-64.

Fonshaw, K. A. (1972). Electrophoretic patterns of strains of Mycoplasma pulmonis. Journal of General Microbiology 72, 493-499.

GouRlay, R. N. \& LeACH, R. H. (1970). A new mycoplasma species isolated from pneumonic lungs of calves (Mycoplasma dispar sp.nov.). Journal of Medical Microbiology 3, I I I-I 23.

Grist, N. R., Ross, C. A. C., Bell, E. J. \& Stotr, E. J. (1966). Methods in Clinical Virology. Oxford: Blackwell Scientific Publications.

HAYFlick, L. \& STANBRIDGe, E. (1967). Isolation and identification of mycoplasma from human clinical material. Annals of the New York Academy of Sciences 143, 608-621.

Hollingdale, M. R. \& Lemcke, R. M. (1969). The antigens of Mycoplasma hominis. Journal of Hygiene $67,585-602$.

KLIENEBERGER, E. (1938). Pleuropneumonia-like organisms of diverse provenance: some results of an enquiry into methods of differentiation. Journal of Hygiene $\mathbf{3}^{8}, 458-476$.

LeMCKe, R. M. (1961). Association of PPLO infection and antibody response in rats and mice. Journal of Hygiene 59, 40I-4I2.

LEMCKE, R. M. (1964). The serological differentiation of mycoplasma strains (pleuropneumonia-like organisms) for various sources. Journal of Hygiene 62, 199-219.

Purcell, R. H., Wong, D. G., Chanock, R. M., Taylor-Robinson, D., Canchola, J. \& Valdesuso, J. (1967). Significance of antibody to mycoplasma as measured by metabolic-inhibition techniques. Annals of the New York Academy of Sciences 143, 664-675.

Somerson, N. L., Reich, P. R., Walls, B. E., Chanock, R. M. \& Weissman, S. M. (I966). Genetic differentiation by nucleic acid homology. II. Genotypic variations within two mycoplasma species. Journal of Bacteriology 92, 3II-317.

TAYLOR-Robinson, D. \& BerRy, D. M. (I969). The evaluation of the metabolic-inhibition technique for the study of Mycoplasma gallisepticum. Journal of General Microbiology 55, I27-I 37.

Taylor-Robinson, D., Martin-Bourgon, C., Watanabe, T. \& Addey, J. P. (I97I). Isolation of Tmycoplasmas from dogs and squirrel monkeys : biological and serological comparison with those isolated from man and cattle. Journal of General Microbiology 68, 97-107.

Taylor-Robinson, D., Purcell, R. H., Wong, D. C. \& Chanock, R. M. (i966). A colour test for the measurement of antibody to certain mycoplasma species based upon the inhibition of acid production. Journal of Hygiene 64, $9 \mathrm{I}-104$.

Taylor-Robinson, D., Somerson, N. L., Turner, H. C. \& Chanock, R. M. (I963). Serological relationships among human mycoplasmas as shown by complement-fixation and gel diffusion. Journal of Bacteriology 85, I26I-I 273 .

Tully, J. G. (1965). Biochemical, morphological and serological characterization of mycoplasma of murine origin. Journal of Infectious Diseases II5, 17 I-1 85 . 